\title{
Experimental Study of Water Infiltration in Unsaturated Horizontal Sand Columns under Various Air Confinement Conditions
}

\author{
Meng Chen $\left(\mathbb{D},{ }^{1,2}\right.$ Zhifang Zhou $\left(\mathbb{D},{ }^{1,2}\right.$ Brent Sleep, ${ }^{3}$ Xingxing Kuang, ${ }^{4}$ Li Mingwei, ${ }^{1}$ \\ and Anchi Shi ${ }^{5}$ \\ ${ }^{1}$ School of Earth Science and Engineering, Hohai University, No. 8 Focheng West Road, Nanjing, China \\ ${ }^{2}$ College of Hydrology and Water Resources, Hohai University, No. 1 Xikang Road, Nanjing, China \\ ${ }^{3}$ Department of Civil \& Mineral Engineering, University of Toronto, Toronto, Canada \\ ${ }^{4}$ School of Environmental Science and Engineering, Southern University of Science and Technology, Shenzhen 518055, China \\ ${ }^{5}$ PowerChina Huadong Engineering Corporation Limited, Hangzhou, China
}

Correspondence should be addressed to Zhifang Zhou; zhouzf@hhu.edu.cn

Received 21 June 2019; Accepted 1 October 2019; Published 18 December 2019

Academic Editor: Julie K. Pearce

Copyright (c) 2019 Meng Chen et al. This is an open access article distributed under the Creative Commons Attribution License, which permits unrestricted use, distribution, and reproduction in any medium, provided the original work is properly cited.

\begin{abstract}
The process of water infiltration into initially dry sand was studied in horizontal sand columns under various airtight conditions. To investigate the interrelations among water inflow behavior, air pressure, air confinement effect, and vent effectiveness in unsaturated porous media experiencing dynamic infiltration, a total of five dynamic infiltration experiments with fixed inlet water pressure were performed with different air vents open or closed along the column length. Visualizations of the infiltration process were accompanied by measurements of water saturation, air pressure, and accumulated water inflow. In a column system with an open end, the absence of air pressure buildup reveals that the vent at the column end can significantly reduce the internal air pressure effects during infiltration, and the air phase can be ignored for this case. However, in columns with a tight end, the coupled air and water flow processes can be divided into two completely different periods. Before the water front passed by the most distant open vent, the internal air pressure effects on retarding dynamic infiltration are negligible, similar to the open end case. After this period, the open vents can certainly influence the inflow behavior by functioning as air outlets while they cannot equilibrate pore air pressure with the atmospheric pressure. The remaining air ahead of the front will be gradually confined and compressed, and the significant increase in air pressure highlights the great role of air pressure buildup in reducing the water infiltration rate. The closer the last open vent was to the water inlet, the higher was the increase in air pressure and the greater was the delaying effect on water infiltration. This work may extend the experimental study of water infiltration into the unsaturated soils with different airtight conditions and provide experimental evidence on these coupled mechanisms among the water and air phases in soils.
\end{abstract}

\section{Introduction}

The influence of air entrapment on water infiltration into unsaturated porous media has been studied for a long time [1-7]. In cases in which the gas phase displaced by the invading liquid can freely escape from the system, the traditional assumptions that soil air pressure remains constant and in equilibrium with atmospheric pressure are valid [8-11]. However, in many cases, the movement of air may be impeded by impervious layers or obstructions, leading to a buildup in air pressure and a reduction in the rate of water infiltration due to the entrapped and compressed air phase [2, 12-14].

The impact of air confinement on the water infiltration process can be significant for a number of natural conditions [15-17]. As reported in Slater and Byers [15], for a finegrained soil underlain by an impervious rock or clay, the rainfall might seal the surface soil and further resist the air escape. Weeks [16] and Guo et al. [5] showed that heavy 
rainfall events might produce the Lisse effect in which heavy rainfall produced air confinement and an increase in air pressure that led to a rise of water level in observation wells. Although vertical infiltration in the unsaturated zone is more common and extensively studied, horizontal air-water flow is also expected to occur in many geological circumstances [6, 18-20]. For example, the tide-induced air-water flow in coastal areas is a typical two-dimensional air-water flow system. As reported in Jiao and Li [18], a two-phase air-water flow model for predicting the tide-induced variation of air pressure in coastal unsaturated zones under no-rain conditions was developed. They provided a full understanding of the interrelations among the barometric pressure variations, sea tides, and rainfall. In addition, Guo and Jiao [6] numerically investigated subsurface air-water flow subjected to a tidal boundary in a coastal two-layered system. They reported that in such an air-confined system, the vertical air flux tends to be dominant in the upper low-permeability layer and the horizontal air flux is expected to be dominant in the lower relatively high-permeability layer, and both the vertical and horizontal airflow would gradually attenuate landward and upward. More importantly, in volcanic rock reservoir areas, the horizontal fault zones or interlayer staggered zones consisting of mud, debris, and gravel are often formed in river mountains due to tectonic activity $[19,20]$. In natural condition, most horizontally developed interlayer staggered zones are initially in the unsaturated state. During reservoir filling, water infiltration into an interlayer staggered zone is also a typical horizontal air-water flow system. As water infiltrates the soil, in regions where the surrounding rock fractures are not developed, the air phase would be expected to be compressed (no airflow boundary), which may contribute a buildup in air pressure and produce a significant effect on retarding the water infiltration process (the horizontal water-air flux tends to be dominant); however, in regions in which some fractures occur in the surrounding rock, a portion of displaced air within the interlayer soils would escape to the surrounding rock mass through these fractures (the vertical water-air flux tends to be dominant). Hence, in unsaturated porous media, experimental investigation of the influence of airflow on horizontal water infiltration in the systems with different airtight conditions is of great importance.

The role of airflow in water infiltration has also been reported in many laboratory tests, and this experimental investigation can be traced to Powers' experiment which showed that the rate of water entrance into soil columns sealed at the base was less than that when the columns were open to the atmosphere at the base [2]. Free and Palmer [21], Wilson and Luthin [22], Peck [8], and Adrian and Franzini [9] have also studied the delaying effects of air pressure buildup on the water percolation rate in vertical, closed columns packed with homogeneous, initially dry sand. In the work of Wilson and Luthin [22], the air pressure reached a peak value of $\sim 11.0 \mathrm{kPa}$ in unvented columns during infiltration, while the corresponding peak air pressure was $\sim 1.4 \mathrm{kPa}$ for vented columns. Adrian and Franzini [9] noted that a smaller reduction in the infiltration rate in fine-grained soils might be observed in comparison with coarse-grained soils. In some work, stratified columns were also considered. By the use of a vertical stratified unsaturated soil column,
Vachaud et al. [23] studied the effects of the air phase on both gravity drainage and constant water infiltration. This delaying effect was measured for both drainage and infiltration. Touma and Vauclin [14] conducted a water infiltration test in vertical, partially saturated columns considering various water boundary conditions applied at the top surface. The results showed that airflow should not be neglected for both flux and ponded conditions. Two types of vertical column were also considered in Latifi et al. [24]: a homogeneous soil column and a two-layered soil column. They showed that air pressure buildup was more significant in the two-layered soil column than in the homogeneous one.

The delaying effect of air pressure on water movement was also observed in some gravity drainage situations if the water drainage rate was higher than the air inflow rate [2529]. Liakopoulos [25] conducted a dynamic drainage experiment in a vertical sand column with an open end; the presence of negative air pressure along the axis indicated that air pressure might have a slightly retarding influence on the drainage behavior. Unlike gravity drainage, more recently, Hou et al. [29] used experimental measurement and numerical modeling to investigate the assumption that air moves without viscous pressure drops (infinitely mobile) in an unsaturated soil column experiencing rapid dynamic drainage. Results of their experiments showed that air pressure gradients within soil could be great and suggested that the assumption of infinite air mobility is a poor assumption in any porous medium experiencing rapid drainage.

Although water vertical infiltration into unsaturated porous media has been extensively investigated, there are few studies that deal with water horizontal infiltration into unsaturated soils at high inlet water pressure. More importantly, the relationship between the airtight condition and the water inflow behavior is unclear. Most of the previous investigators only considered the two extreme cases, including the systems with no air outlets or the systems allowing air to escape freely. No experimental studies have been made in the systems under a range of airtight conditions. Hence, there remains a need for further experimental studies of the interactions among water infiltration, air pressure, vent performance, and air confinement effect during water infiltration into unsaturated porous media.

In this study, a flow visualization system was developed for investigating water horizontal infiltration into unsaturated sand columns. Dynamic infiltration tests were performed under a variety of air confinement conditions with a single or several vents open to allow air to escape from the system at various locations along the column. Water phase movement was tracked with time-domain reflectometry measurements of water saturation at selected locations along the column and with accumulated water inflow. Air pressure at the opposite end of the column was also measured.

\section{Horizontal Infiltration Experiments in Unsaturated Sand Columns}

2.1. Experimental Setup. Infiltration experiments of water displacing air were performed in horizontal sand columns 


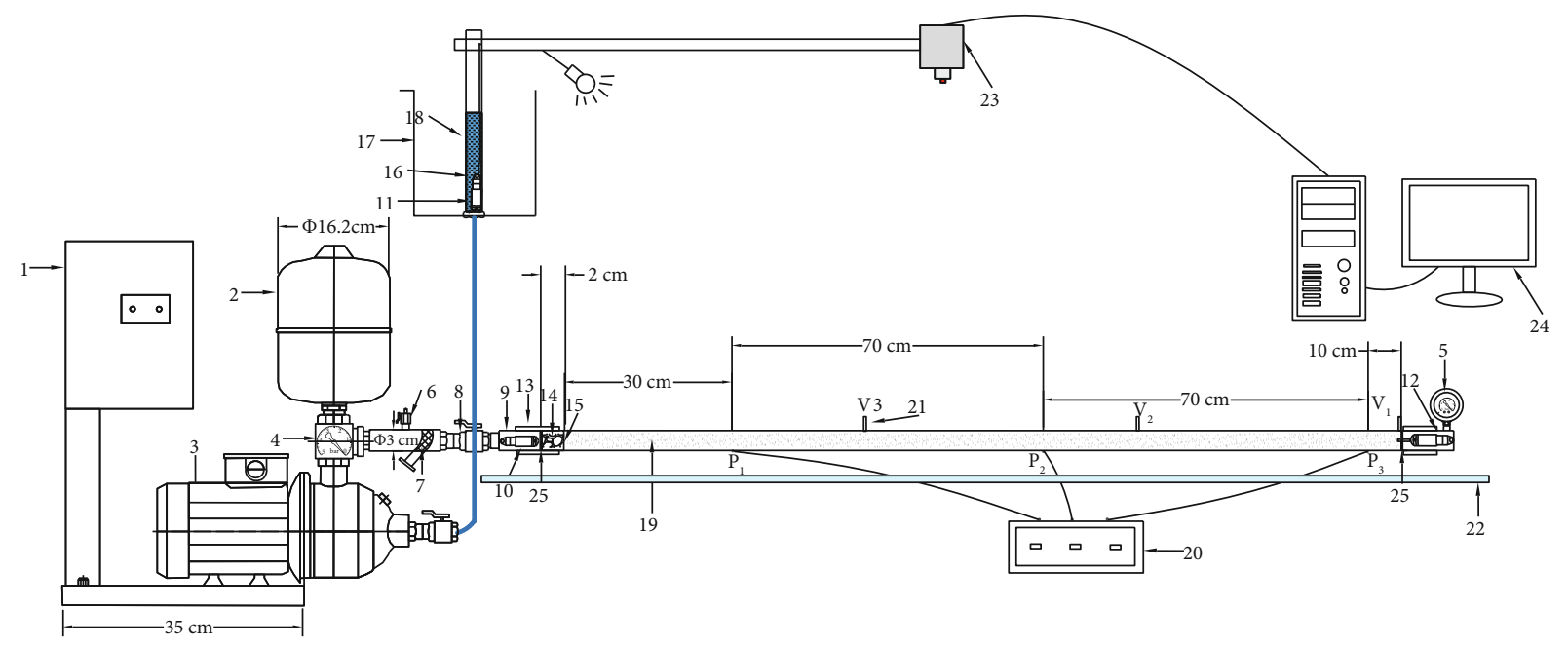

FIgURE 1: Schematic diagram of the fluid-fluid flow system.

(Figure 1). The system consisted of a transparent Perspex pipe of $182 \mathrm{~cm}$ length, $3.01 \mathrm{~cm}$ inside diameter, and $4.62 \mathrm{~cm}$ external diameter; a CCD camera (Sony FCB-EX48EP); a water supply system (Wilo, MHIL403); a TDR system to measure soil moisture (range $0-100 \%$, accuracy 3\%, resolution $0.1 \%$; HSTL-102STR); and several pressure wireless data loggers (18 mm diameter $\times 90 \mathrm{~mm}$ long, range $0 \sim 98.6 \mathrm{kPa}$, resolution $25 \mathrm{~Pa}$; Micro-Diver, Schlumberger). Details of this system are shown in Figure 1. All experiments were performed using the sand with grain size ranging from 0.05 to $2 \mathrm{~mm}$. The dry sand was packed into the column to a length of $180 \mathrm{~cm}$ by $3.01 \mathrm{~cm}$ inner diameter.

The time evolution of water saturation at three positions $\mathrm{P}_{1}-\mathrm{P}_{3}(x=30,100$, and $170 \mathrm{~cm}$ from the inlet $)$ was measured with a time-domain reflectometry system (TDR) by inserting $3.6 \mathrm{~cm}$ long probes with a $0.8 \mathrm{~cm}$ insulating layer into the sand column. To continuously record the air pressure at the farther end of the column, a pressure wireless monitoring sensor was put in a perfect fit and tightly enclosed stainless steel sleeve (with a minimum dead volume); enabling a sealed connection with the column end. To measure the inlet water pressure, a data logger was placed in the inlet pipe. The air pressure and soil moisture were recorded at $30 \mathrm{~s}$ intervals.

The potential influence of air transport on water infiltration under various vented column systems was investigated. To this end, three air vents $\mathrm{V}_{1}-\mathrm{V}_{3}(22.1 \mathrm{~mm}$ long $\times 8.5 \mathrm{~mm}$ ID) were installed in the top side of the horizontal column at different positions ( $x=180,120,60 \mathrm{~cm}$ from the inlet) (see Figure 1). When all vents are closed, the sand column is airtight on all boundaries. Various air confinement conditions can be achieved by controlling the vent switching. A total of five scenarios with the same initial condition but different combinations of vents open or closed were performed: (1) Expt. \#1 with vent $V_{1}$ open (the column end) and all other vents closed; (2) Expt. \#2 with vent $V_{2}$ open; (3) Expt. \#3 with vent $\mathrm{V}_{3}$ open; (4) Expt. \#4 with all vents $\mathrm{V}_{1}-\mathrm{V}_{3}$ open; and (5) Expt. \#5 with vents $\mathrm{V}_{2}$ and $\mathrm{V}_{3}$ open. Summary of the experimental conditions is presented in Table 1.
2.2. Procedures. Prior to packing, we first have the column vertical. To prevent the sand loss, a $40 \mu \mathrm{m}$ pore size porous plate with $2 \mathrm{~mm}$ thickness was bolted to the column bottom end. The column was filled in ninety layers $(2 \mathrm{~cm}$ for each layer) to avoid layering or preferential flow, with each layer carefully poured, fully mixed, firmly tapped, and compacted. After packing of the sand, a $2 \mathrm{~cm}$ layer of high-permeability gravel (grain size ranges from 5 to $10 \mathrm{~mm}$ ) was placed at the surface of the sand to promote water infiltration. After that, we bolted a $4 \mathrm{~mm}$ pore size porous plate to the column top end to prevent packing loss, and then, the column was turned to a horizontal position.

We connected the right-hand end of the column to the stainless steel sleeve with a built-in air pressure wireless monitoring sensor through a silicone hose, as well as the left end of the column to the inlet pipe with a built-in water pressure wireless monitoring sensor. Note that since there might exist a viscous resistance to water inflow in a pipe, the real inlet water pressure was typically lower than the set value. So a wireless pressure sensor was also placed within the inlet pipe to measure transient inlet water pressure. A hydrophobic Teflon (PTFE) membrane $(130 \mu \mathrm{m}$ thickness, $10 \mu \mathrm{m}$ pore size; Millipore, LCWP04700) was glued to the one end of the air vent in contact with the soil. The water draining from the vents was collected using a plastic pipe. Furthermore, the pressure data logger was placed in the water supply pipe (19.8 $\mathrm{mm}$ ID $\times 951 \mathrm{~mm}$ long) as well as each water collecting pipe to calculate inflow or outflow volume (note that the resolution is $0.77 \mathrm{~cm}^{3}$ ) based on the measurements of hydrostatic pressure. The CCD camera and TDR system were connected to the computer for recording. Before opening the water inlet valve, air within the inlet pipe was fully discharged. We then closed all vents except $V_{1}$ and regulated the water supply system to a fixed water pressure of $30 \mathrm{kPa}$. Finally, the water inlet valve was opened, and water dyed with Brilliant Blue FCF (CI 42090) was pumped into the column. It should be noted that in this unsaturated infiltration system, all controlled resistances to flow beyond the baseline system resistances were reduced to a minimum. 
TABLE 1: Design of the five experiments.

\begin{tabular}{lccccc}
\hline Air vents & Expt. \#1 & Expt. \#2 & Expt. \#3 & Expt. \#4 & Expt. \#5 \\
\hline $\mathrm{V}_{1}(180 \mathrm{~cm})$ & Open* & Shut & Shut & Open & Shut \\
$\mathrm{V}_{2}(120 \mathrm{~cm})$ & Shut & Open* & Shut & Open & Open \\
$\mathrm{V}_{3}(60 \mathrm{~cm})$ & Shut & Shut & Open* & Open* & Open* \\
\hline
\end{tabular}

* indicates the open valve farthest from the column inlet.

When equilibrium was reached (in water-saturated state), a falling-head test was performed to determine the saturated hydraulic conductivity of the packing. In Expts. \#2-\#5, compared to Expt. \#1, only the vents that are open are different, but other procedures remain the same. The porosity and bulk density of the packings were measured by the method provided by Tan [30]. The measured porosity, initial and saturated water content, and bulk density of the packings are, respectively, $0.47,0.15,0.43$, and $1.67 \mathrm{~g} / \mathrm{cm}^{3}$. The temperature of the room in which the dynamic experiments were carried out varied from $17^{\circ} \mathrm{C}$ to $21^{\circ} \mathrm{C}$.

\section{Results}

As water infiltration proceeds, the air phase in the unsaturated zone is gradually displaced by the invading water, accompanied by an increase in air pressure and water saturation. We characterize general distributions of the saturated, transition, and unchanged zones when the wetting front first reaches (where the saturation begins to increase from the initial water saturation) the selected positions $t_{\text {wet }}\left(t_{\text {wet1 }}, t_{\text {wet2 }}\right.$, and $t_{\text {wet3 }}$ for points $\mathrm{P}_{1}-\mathrm{P}_{3}$; see Figure 1 for their positions). We also analyze the water saturation $S_{w}$ at points $\mathrm{P}_{1}-\mathrm{P}_{3}$, the air pressure $p_{\mathrm{a}}$ at the column end, and the accumulated water volume $Q_{\text {in }}$ through the column inlet. Note that the measured air pressure is a relative value based on an atmospheric pressure of $101.3 \mathrm{kPa}$. The visual observations, as well as these measurements, jointly contribute to the investigation of these coupled air-water flow processes.

3.1. The Unsaturated Water Infiltration. Initially owing to the water pressure gradient near the inlet surface, water began to fill the pore space by displacing and compressing the air phase within the column. Ahead of the water front, a zone approaching the saturated state with some trapped air was continuously evolving and pushing air towards the end of the column. For Expts. \#1-\#3, as depicted in Figure 2, a deeper blue color indicates a larger degree of water saturation $S_{\mathrm{w}}$, allowing us to approximately distinguish the three particular zones by color shade, which refer to the saturated zone $\left(S_{\mathrm{w}}\right.$ approaches 1$)$, transition zone $\left(S_{\mathrm{w}}\right.$ over the initial water saturation but below 1), and unchanged zone ( $S_{\mathrm{w}}$ is equal to the value of initial saturation).

Significant differences between the lengths of the transition zone in different tests can be observed. For each test, as time passed, the transition zone gradually became wider (transition zone at $t_{\text {wet3 }}$ for Expts. \#1-\#3 is 8, 13, and $21 \mathrm{~cm}$, respectively). Interestingly, by comparison of the resulting transition zone width between Expts. \#1-\#3, from Figure 2, Expt. \#3 yielded the largest transition zone width at each

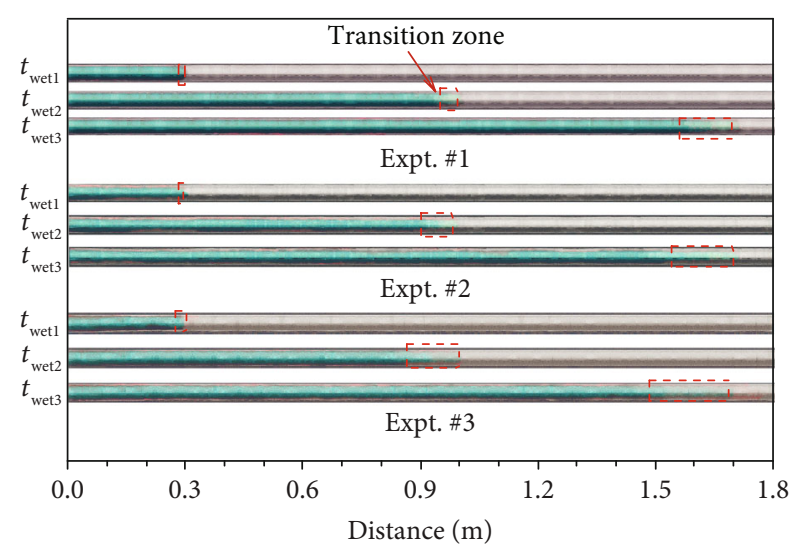

FIGURE 2: Visual imaging of the infiltration process in Expts. \#1-\#3. All snapshots show the general distribution of the saturated zone (red dotted line), transition zone (green dotted line), and unchanged zone (yellow dotted line) at the times that the wetting front reaches the positions $\mathrm{P}_{1}-\mathrm{P}_{3}$.

selected time step $\left(2,14\right.$, and $21 \mathrm{~cm}$ at $t_{\text {wet } 1}-t_{\text {wet } 3}$, respectively), whereas the lowest width can be measured from Expt. $\# 1\left(2,6\right.$, and $8 \mathrm{~cm}$ for $t_{\mathrm{wet} 1}-t_{\mathrm{wet} 3}$, respectively). These indicate that the infiltration processes with different vents open are dramatically different. To further analyze and explain these features, the quantitative measurements in Expts. \#1-\#3 are presented next.

The time-saturation curves of the invading water at points $\mathrm{P}_{1}-\mathrm{P}_{3}$ are plotted in Figure 3. As can be seen, there was a gradual increase in water saturation $S_{\mathrm{w}}$ for all points, eventually reaching a peak value approaching 1 at different times. From Figure 3, the times when the wetting front first reached the points $t_{\text {wet }}$ are almost identical with those from the visualizations (Figure 2). Compared to Expt. \#1, at each point, there was an increase in $t_{\text {wet }}$ and $\Delta t$ (the time taken from wetting to saturation) for all experiments. In particular, comparing Expt. \#1 to Expt. \#3, there was an increase up to $80 \%$ in $\Delta t$ at point $\mathrm{P}_{3}$ (increased from $13 \mathrm{~min}$ for Expt. \#1 to $117 \mathrm{~min}$ for Expt. \#3).

Concerning the distance of the open vent from the inlet $x_{\mathrm{v}}$, Expt. \#1 with $\mathrm{V}_{1}$ open gives the largest $x_{\mathrm{v}}$ of $180 \mathrm{~cm}$ (the column end), followed by Expt. \#2 with $x_{\mathrm{v}}=120 \mathrm{~cm}\left(\mathrm{~V}_{2}\right)$ and Expt. \#3 with $x_{\mathrm{v}}=60 \mathrm{~cm}\left(\mathrm{~V}_{3}\right)$. Clearly, the results from Figures 2 and 3 strongly suggest that there was a close relation between the value of $x_{\mathrm{v}}$ and the characteristics of the infiltration process. Specifically, the infiltration rate was slowed down after the wetting front reached $x_{\mathrm{v}}$, and this delaying effect became more pronounced in tests with a smaller $x_{\mathrm{v}}$, as evidenced by the following: (i) from Figure 2, the transition zone width in Expt. \#3 with the smallest $x_{\mathrm{v}}$ of $60 \mathrm{~cm}$ was larger than that of the others at any period which indicates that the slowest infiltration rate was measured; (ii) for Expts. \#2 and \#3 $\left(0 \mathrm{~cm}<x_{\mathrm{v}}<180 \mathrm{~cm}\right)$, we noted a significant increase in transition zone width after the wetting front passed by $x_{\mathrm{v}}$; and (iii) for the three experiments, as $x_{\mathrm{v}}$ increased, a rapid drop in $t_{\text {wet }}$ followed for all points, showing that the corresponding test had a more rapid infiltration rate; that is, Expt. \#1 with the largest $x_{\mathrm{v}}$ of $180 \mathrm{~cm}$ produced the 


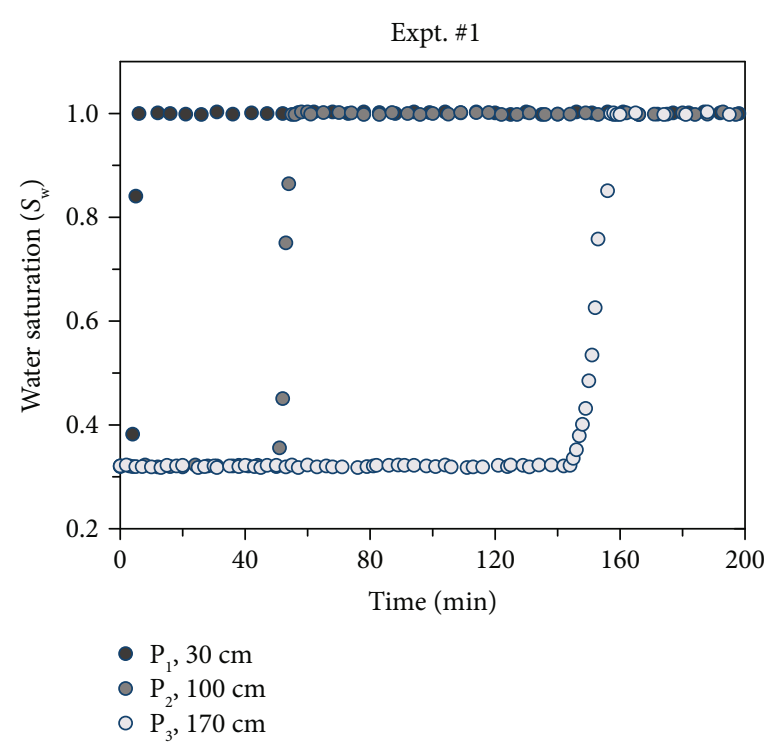

(a)

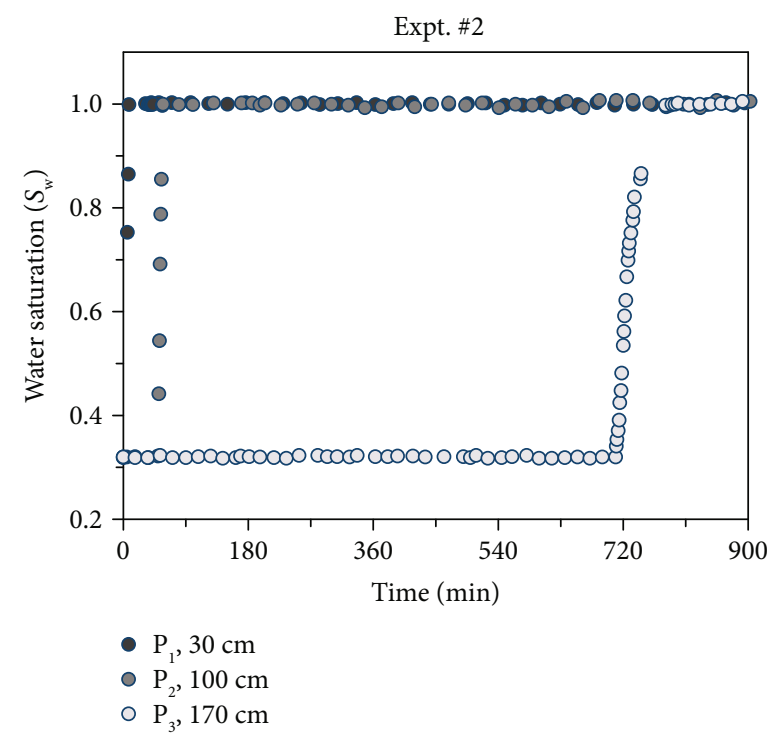

(b)

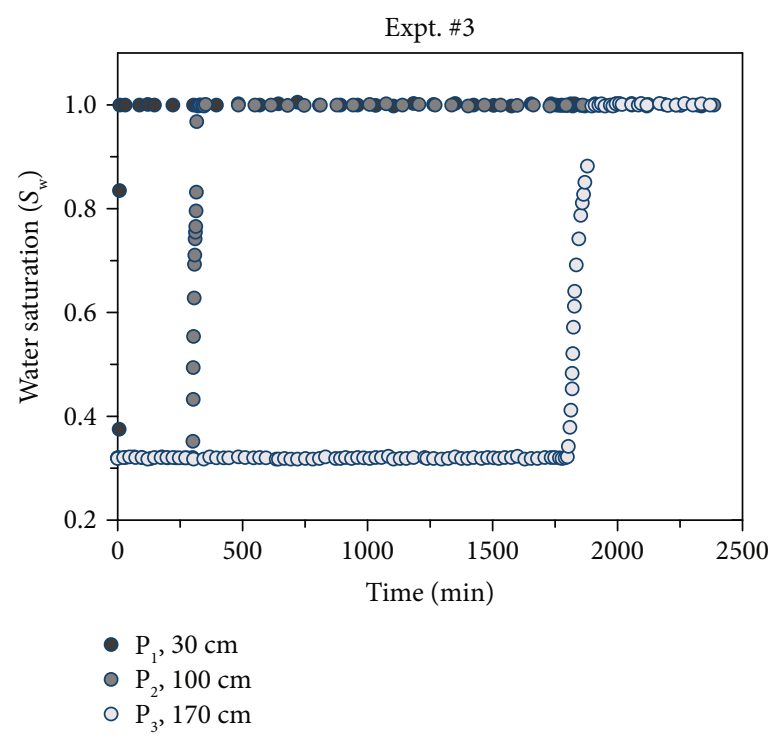

(c)

FIgURE 3: The time evolution of water saturation at selected points $P_{1}-P_{3}$ for Expts. \#1-\#3.

highest infiltration rate among the three. By inspecting the variation in air pressure at the farther end of the column (Figure 4), we gain insight into the air movement and further discuss the relationships between the value of $x_{\mathrm{v}}$, internal air pressure, and inflow behavior.

3.2. The Process of Air Transport. For Expt. 1 with vent $V_{1}$ open, the air pressure at the column end remained steady at about zero during the whole infiltration process indicating no air pressure buildup at the column end (not shown). However, from Figure 4, in both Expt. \#2 and Expt. \#3 $\left(x_{\mathrm{v}}<180 \mathrm{~cm}\right)$, the air pressure increased from the atmospheric pressure to different peaks $p_{a \text { apeak }}$; Expt. \#2 and Expt. $\# 3$, respectively, produced a peak air pressure $p_{\text {a,peak }}$ of $26.03 \mathrm{kPa}$ and $28.01 \mathrm{kPa}$, smaller than the fixed inlet water pressure of about $30 \mathrm{kPa}$. It is important to note that for Expt. \#2 and Expt. \#3, the air pressure did not show an instantaneous increase at the beginning of water infiltration; from the measurements, the initial buildup in air pressure $t_{\text {pa,start }}$ had a lag of $74 \mathrm{~min}$ and $16 \mathrm{~min}$ for Expt. \#2 and Expt. \#3, respectively, consistent with the times that the wetting front first reached the open vent $x_{\mathrm{v}}$, suggesting that the increase in air pressure did not occur until the wetting front passed by the open vent (in fact, the possible air pressure drop within the unsaturated zone could be identified; this behavior will be further presented in Discussion). Evidently, the closer the open vent was to the inlet (smaller $x_{\mathrm{v}}$ ), the higher was the peak value in air pressures $p_{a, p e a k}$ and the longer was the time for air pressure to begin increasing $t_{\mathrm{pastar}}$. 


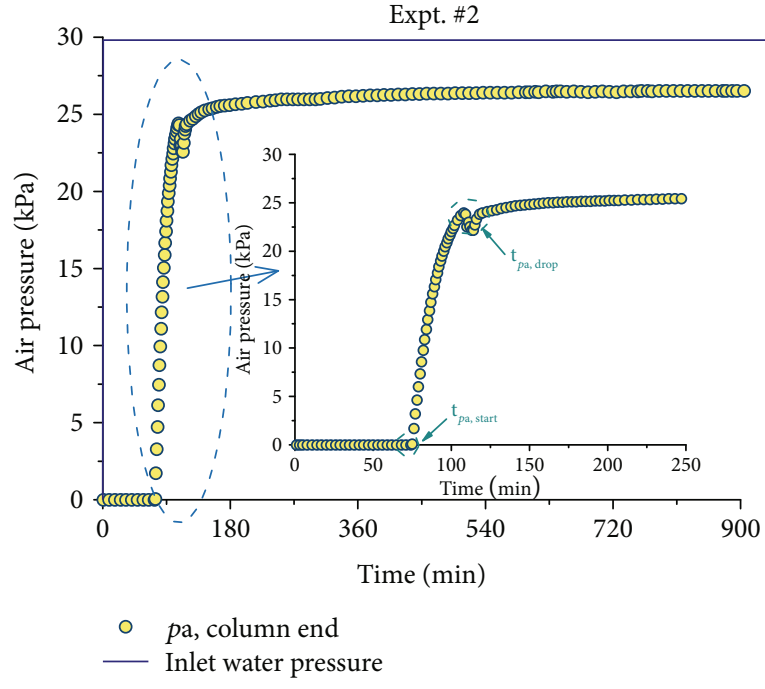

(a)

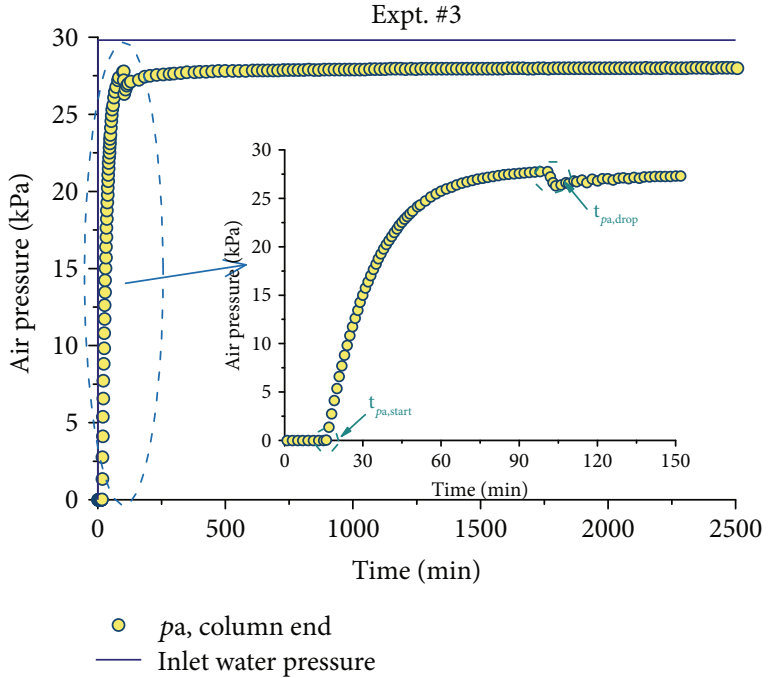

(b)

FIgURE 4: The variation in air pressure with time at the column end for (a) Expt. \#2 and (b) Expt. \#3, shown at two time scales.

It is also important to note that for column systems with $x_{\mathrm{v}}<180 \mathrm{~cm}$, once the water passes by the last open vent, the flow of air to this vent would be impeded by the continuous water phase. Assuming that all air is trapped beyond would be unable to escape and would be compressed ahead of the advancing front, one may calculate a theoretical peak air pressure. Comparing these values to the measurements of air pressure indicates that a portion of air beyond must have vented from the system through open vents behind the front (more details are presented in Discussion). Interestingly, as shown in Figure 4, a sudden drop in air pressure for Expts. $\# 2$ and $\# 3$ at $t_{\mathrm{pa} \text {,drop }}\left(t_{\mathrm{paddrop}}=107\right.$ min for Expt. \#2; $t_{\mathrm{padrop}}$ $=101 \mathrm{~min}$ for Expt. \#3) was measured; it is possible that the pressure of the compressed air phase (remained along the top of the horizontal column) would increase to a critical value $p_{\mathrm{a}, \text { crit }}\left(p_{\mathrm{a} \text {,crit }}=23.94 \mathrm{kPa}\right.$ for Expt. \#2; $p_{\mathrm{a} \text {, crit }}=27.78 \mathrm{kPa}$ for Expt. \#3) allowing air to escape through the last open vent. In the period of falling air pressure, the air outflow rate was expected to exceed the water inflow rate. The singularity in air pressure in this period is consistent with visual observations that there was a continuous venting of air from the last open vent after the front had passed the last open vent. After this period, as the rate of imbibition of water exceeded the rate of escape of air, a period of increasing air pressure followed and finally remained at peak value.

In Figure 5, the cumulative water imbibed $Q_{\text {in }}$ for Expts. $\# 1-\# 3$ at various times are compared. For all tests, as time increased, a gradual increase in $Q_{\text {in }}$ followed and then maintained at different peak values at the end of the test, indicating that the differences in flow behavior between the three experiments could be significant over the duration of imbibition. The experiment with a smaller $x_{\mathrm{v}}$ produced a smaller peak inflow $Q_{\text {in }}$ (the total amount of water imbibed), and the peak water imbibed $Q_{\text {in }}$ was $\sim 392.04 \mathrm{~cm}^{3}$ and $\sim 366.52 \mathrm{~cm}^{3}$ for the systems with a $x_{\mathrm{v}}$ of $180 \mathrm{~cm}$ and $120 \mathrm{~cm}$, respectively, compared with $\sim 319.08 \mathrm{~cm}^{3}$ for the system with a $x_{\mathrm{v}}=60 \mathrm{~cm}$. It is also interesting to note that, as shown in Figure 5, a sud- den drop in the inflow rate (the slope of accumulated water imbibed versus time curve) occurred for Expt. \#2 and Expt. \#3 after a particular time defined here as $t_{\mathrm{Q}, \text { turn }}$ (note that this behavior was absent in Expt. \#1). This abrupt change is likely the result of the wetting front just passing by the open vent at $t_{\mathrm{Q} \text {,turn }}$, as the measured $t_{\mathrm{Q} \text {,turn }}$ was, respectively, 77 min and 18 min for Expt. \#2 and Expt. \#3, consistent with the time that the wetting front first reached the respective open vent $x_{\mathrm{v}}$. This result suggests that before $t_{\mathrm{Q} \text {,turn }}$, air in pores displaced by the invading water could easily escape from the open vent and there was no air pressure buildup, and as a result, the inflow differences between the three were relatively small. However, after this period, the advancing front has passed by the open vent and the air phase was pushed forward and compressed, leading to a reduced water infiltration rate. This is why extremely different flow behaviors could be observed within the three experiments. The results in Figure 5 evidence, once again, that the horizontal infiltration process in unsaturated sand column is closely tied to the position of the vent which air can escape.

While the above results did report the differences in inflow behavior and internal air pressure between the three experiments with different vents open, only a single vent to discharge air was used, and the performance of the use of multiple vents is not clear. The question remains: Can the use of multiple air vents strongly impact water inflow behavior and internal air pressure? To solve this question, we performed two additional infiltration experiments with three (open $\mathrm{V}_{1}, \mathrm{~V}_{2}$, and $\mathrm{V}_{3}$ for Expt. \#4) or two (open $\mathrm{V}_{2}$ and $\mathrm{V}_{3}$ for Expt. \#5) different vents open.

Examination of air pressure variation with time (not shown) in Expt. \#4 shows that there was no increase in air pressure over the entire infiltration process, similar to the result of Expt. \#1 as expected. Figure 6 shows a replicate of Expt. \#2 in Figure 4, but with the addition of a vent $\mathrm{V}_{3}$ at $60 \mathrm{~cm}$ from the inlet. One interesting observation is that, despite the differences in the open vents between Expt. \#2 


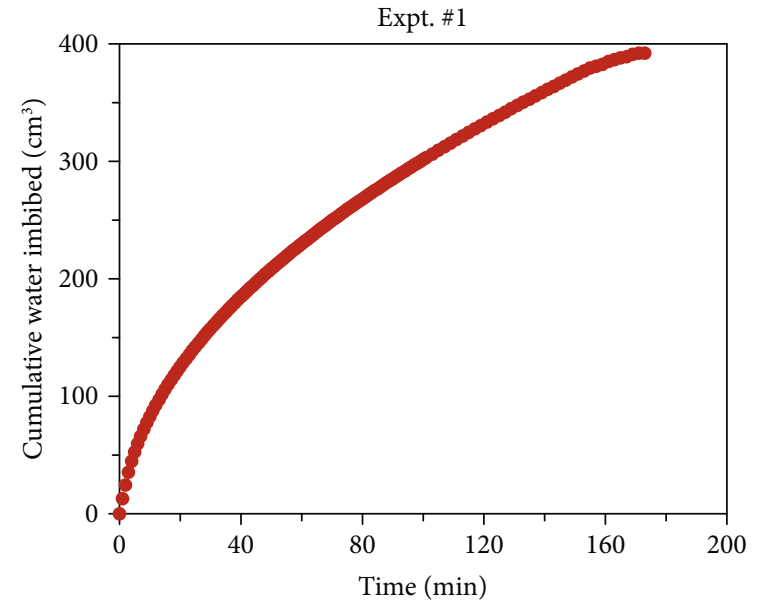

(a)

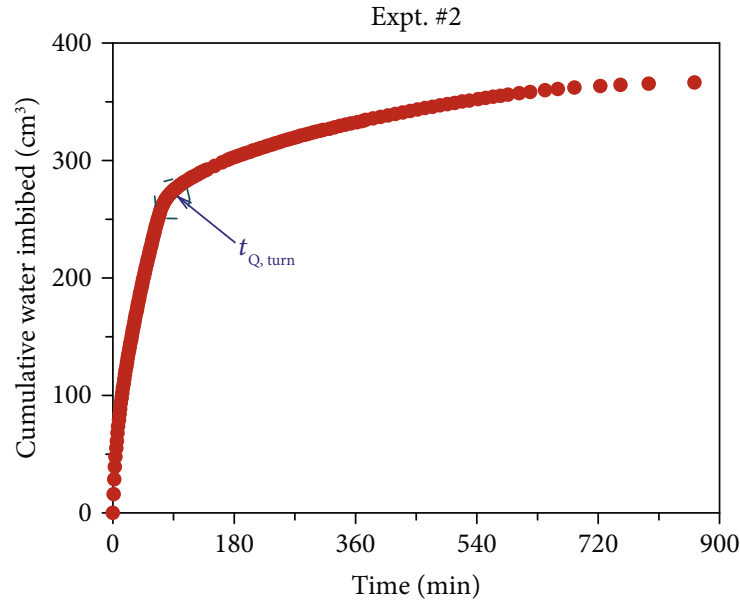

(b)

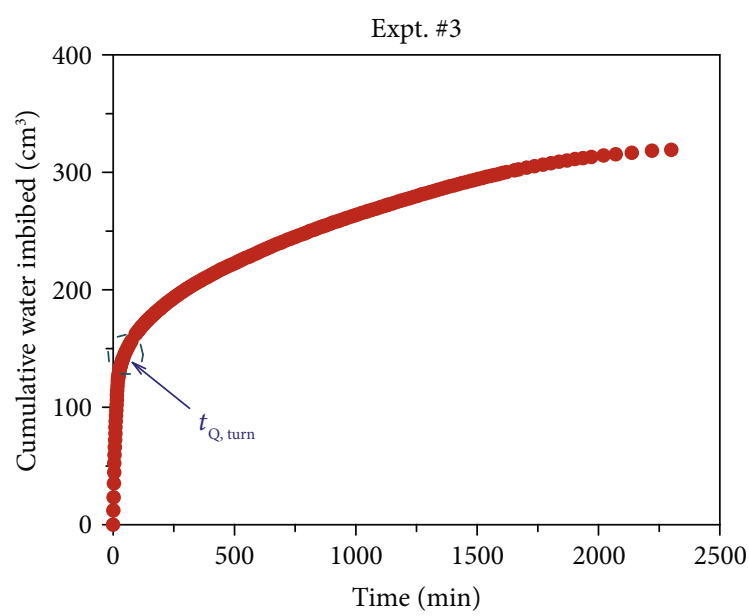

(c)

FIgURE 5: The cumulative water imbibed as a function of time for experiments 1-3.

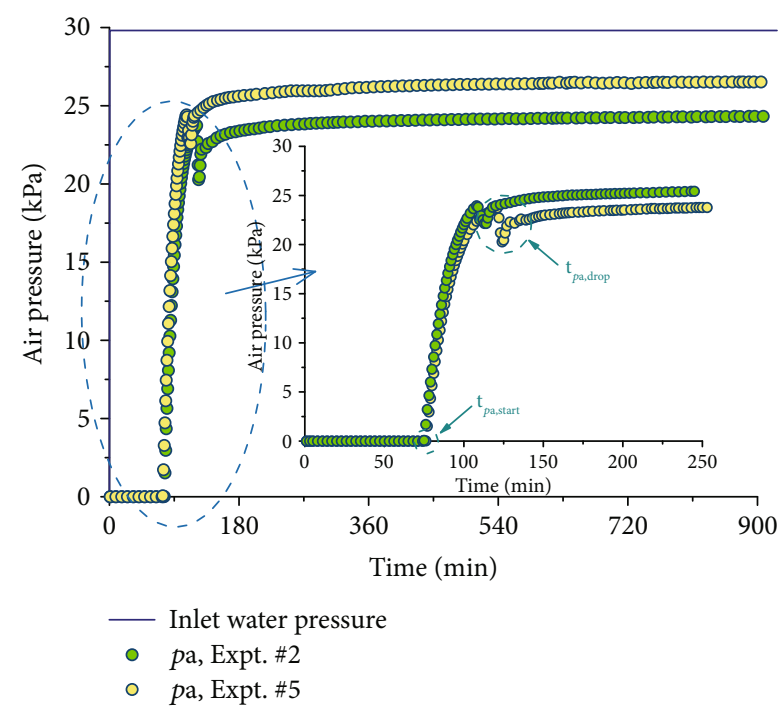

Figure 6: The comparison of air pressure (at the column end) between Expt. \#2 and Expt. \#5, shown at two time scales. and Expt. \#5, the time that air pressure started to buildup $t_{\mathrm{pa}, \text { start }}$ of the two was approximately the same and equal to about $75 \mathrm{~min}$. In addition, it is also interesting to note that the similarity in air pressure between Expt. \#2 and Expt. \#5 could also be observed after the onset of air pressure buildup (the differences in the curve of air pressure versus time between the two were small), with differences becoming evident when approaching to peak air pressure $p_{\text {a,peak }}\left(p_{\text {a,peak }}\right.$ is equal to $26.03 \mathrm{kPa}$ in Expt. \#2, larger than that in Expt. \#5 with $p_{\text {a,peak }}=24.33 \mathrm{kPa}$ ). Clearly, the difference in air pressure variation with the time between Expt. \#2 and Expt. \#5 was relatively small during the whole infiltration processes.

Furthermore, the comparisons of cumulative water imbibed over time between Expt. \#1 and Expt. \#4, as well as between Expt. \#2 and Expt. \#5, are both plotted in Figure 7. It is clear from Figure 7(a) that, despite Expt. \#4 with the addition of two vents open $\left(V_{2}\right.$ and $\left.V_{3}\right)$ compared to Expt. $\# 1$, the difference in water imbibed between Expt. \#1 and Expt. \#4 was subtle over the course of infiltration. In addition, from Figure 7(b), it is interesting to note that before $75 \mathrm{~min}$ (the time period corresponding to the air pressure that remained constant at the atmospheric pressure), the water 


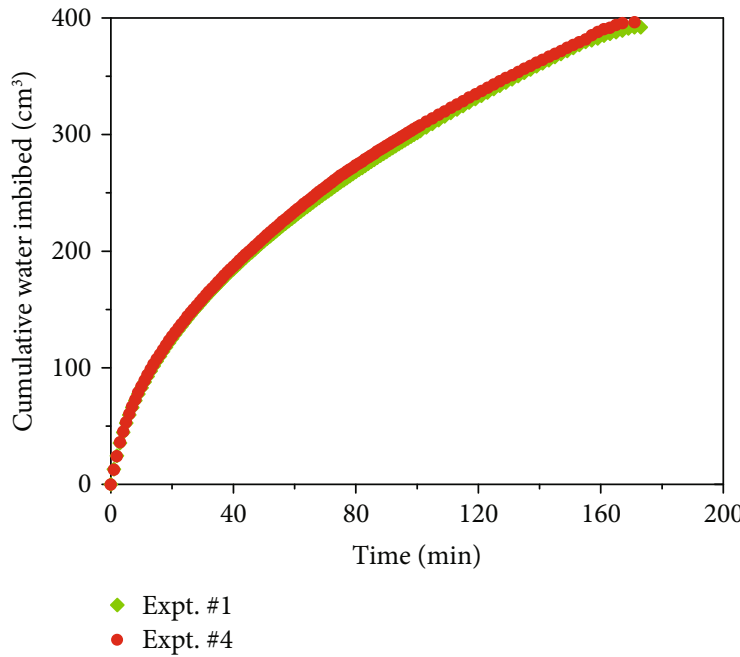

(a)

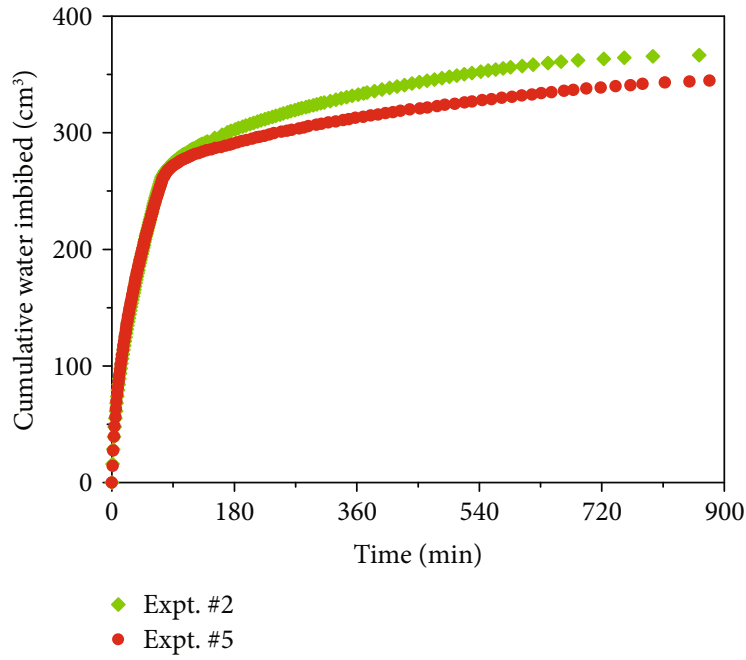

(b)

Figure 7: The comparisons of cumulative water imbibed between (a) Expt. \#1 and Expt. \#4, as well as between (b) Expt. \#2 and Expt. \#5.

imbibed curve in Expt. \#5 was similar and virtually indistinguishable compared to Expt. \#2. After this period, despite an abrupt reduction in the inflow rate observed in both two experiments, the inflow curves failed to converge, with peak inflow $Q_{\text {in }}$ of $\sim 366.52 \mathrm{~cm}^{3}$ for Expt. \#2, larger than that for Expt. \#5 with peak inflow $Q_{\text {in }}$ of $\sim 344.58 \mathrm{~cm}^{3}$.

Concerning the open vent farthest from the inlet, its distance from the inlet is defined here as $x_{\text {far }}$, i.e., $180 \mathrm{~cm}$ for Expt. \#1 and Expt. \#4, $120 \mathrm{~cm}$ for Expt. \#2 and Expt. \#5, and $60 \mathrm{~cm}$ for Expt. \#3. It is interesting to consider the relationship between the value of $x_{\text {far }}$ and the features of the infiltration process. The results from Figures 6 and 7 indicate that, even though the open vents were different, the very similar wetting processes were observed for column systems with the same $x_{\text {far }}$, as evidenced by the following: (i) the curves of water inflow and air pressure over time are quite similar between Expt. \#1 and Expt. \#4 (with the same $x_{\text {far }}$ of $180 \mathrm{~cm}$ ); (ii) comparing Expt. \#2 with Expt. \#5, despite the differences in their open vents, the wetting process in Expt. \#5 with $x_{\text {far }}$ of $120 \mathrm{~cm}$ is, in general, also similar to that in Expt. \#2 which has the same $x_{\text {far }}$. These results indicate that for any specific column system, the location of the last open vent is one of the key factors influencing the characteristics of the infiltration process. The closer the last open was to the inlet, the higher was the peak value in air pressure, contributing to a smaller air confinement effect and a slower wetting process. It is also important to note that for column systems with the same $x_{\text {far }}$, the use of multiple air vents should also be more effective in reducing air pressure effect.

To describe the hydraulic properties of the packings, we choose the measured water saturation data from Expt. \#1 (airflow can be ignored) to determine the two unknowns $\alpha$ and $m$ in the van Genuchten model, which is widely used to describe the soil-water characteristic curve as follows [31]:

$$
S_{\mathrm{e}}=\left\{\begin{array}{l}
{\left[1+\left(\alpha p_{\mathrm{c}}\right)^{n}\right]^{-m}, \quad p_{\mathrm{c}}>0,} \\
1, \quad p_{\mathrm{c}} \leq 0 .
\end{array}\right.
$$

The unsaturated hydraulic conductivity in the VG model is defined as

$$
K=K_{\mathrm{sat}} S_{\mathrm{e}}^{1 / 2}\left[1-\left(1-S_{\mathrm{e}}^{1 / m}\right)^{m}\right]^{2}
$$

where $K_{\text {sat }}=1.76 \times 10^{-5} \mathrm{~m} / \mathrm{s}$ is the saturated hydraulic conductivity determined by the falling-head tests; $S_{\mathrm{e}}$ is the effective degree of water saturation, $S_{\mathrm{e}}=\left(\theta-\theta_{\mathrm{r}}\right) /\left(\theta_{\mathrm{s}}-\theta_{\mathrm{r}}\right) ; \theta_{\mathrm{r}}$ and $\theta_{\mathrm{s}}$ are the residual and saturated volumetric water content, respectively; $\alpha$ is the reciprocal of the air entry pressure; $n$ is a measure of the pore size distribution; and $m=1-1 / n$ $(0<m<1)$.

There are four unknowns in the VG empirical model, namely, $\alpha, n, \theta_{\mathrm{s}}$, and $\theta_{\mathrm{r}}$. The parameter $\theta_{\mathrm{r}}$ can be estimated by a higher matrix suction (e.g., 1.5 MPa). The parameters $\alpha$ and $n$ were fit using the soil moisture characteristic curve. We first assumed the search interval of the unknowns, and the prediction of water saturation at the selected points was obtained by single-phase unsaturated flow modeling (Richards equation). The estimated vector of the soil hydraulic parameter is $\mathbf{F}=(\alpha, n)$, and the mathematical model for the inversion of parameters is

$$
\mathbf{F}_{*}=\left\{\mathbf{F} \mid \min \left[\sum_{t=1}^{n} \sum_{l=1}^{m} \omega_{t, l}\left(S_{t, l}^{*}-S_{t, l}\right)^{p}\right]^{1 / p}\right\},
$$

where the norm value $p=2$ corresponds to the least-squares method which is the most common approach for nonlinear fitting, $S_{t, l}^{*}$ is the measured water saturation for point $l$ at time $t, S_{t, l}$ is the corresponding numerical prediction, and $\omega_{t, l}$ is the weighted value. The optimization objective function is $\min [\mathbf{F}=(\alpha, n)]$.

The value of the unknowns was determined using the Levenberg-Marquardt algorithm for least-squares estimation of nonlinear parameters. The measured parameters were $\theta_{\mathrm{s}}$ 
$=0.43$ and $\theta_{\mathrm{r}}=0.07$, and the fitted parameters were $n=2.3$ and $\alpha=8.72 \times 10^{-4} \mathrm{~Pa}^{-1}$.

From the above results, the pore air at a certain point within the unsaturated zone is compressed by the invading water, leading to an increase in air pressure, and then, pore air at this point is gradually displaced by water. When the pores of this point approach the water-saturated state, the transition from a continuum to a discrete state may occur for residual air in pores, as presented in Figure 8. From the classical Young-Laplace theory of capillary hydrostatics, an equilibrium interface between the gas and liquid phases (or between two immiscible fluids) as a result of capillary forces is identified by an equation:

$$
p_{\mathrm{c}}=p_{\mathrm{a}}-p_{\mathrm{w}}=2 \gamma H=\gamma\left(\frac{1}{R_{1}}+\frac{1}{R_{2}}\right),
$$

where $\gamma=7.28 \times 10^{-2} \mathrm{~N} / \mathrm{m}\left(T=20^{\circ} \mathrm{C}\right)$ is the surface tension, $H$ is the mean curvature at each point on the interface, and $R_{1}$ and $R_{2}$ are the corresponding principal radii of curvature.

When the continuous air in pores becomes discontinuous, if we know the saturation-capillary pressure relationship or the variations in air pressure and water pressure with time, the number of air bubbles per unit volume can be estimated. For instance, in Expt. \#1, we assume $R$ is the average radius of air bubbles in soil pores, the water saturation of point $\mathrm{P}_{3}$ is $S_{\mathrm{w}}=0.85$ at $t=156 \mathrm{~min}$, and the space occupied by the discrete bubbles in a unit volume $\left(V_{\mathrm{u}}=1 \mathrm{~cm}^{3}\right)$ is $V_{\mathrm{b}}=\phi\left(1-S_{\mathrm{w}}\right) V_{\mathrm{u}}=0.0705 \mathrm{~cm}^{3}$, with a capillary pressure $p_{c}$ of $513 \mathrm{~Pa}$ from the saturation-capillary pressure relationship, where $\phi=0.47$ is the sample porosity. The average bubble radius at point $\mathrm{P}_{3}$ is obtained by substituting the capillary pressure $p_{\mathrm{c}}=513 \mathrm{~Pa}$ into equation (4), i.e., $R=R_{1}=R_{2}=2.78 \times 10^{-2} \mathrm{~cm}$ contributing to the mean bubble volume $V_{\mathrm{m}}=9 \times 10^{-5} \mathrm{~cm}^{3}$. Accordingly, the number of air bubble per unit volume in Expt. \#1 for point $\mathrm{P}_{3}$ at $t=156 \min$ is $V_{\mathrm{b}} / V_{\mathrm{m}}=783$.

\section{Discussion}

Many investigators have attempted to use vents to equilibrate soil air with the atmosphere, both in dynamic drainage tests $[23,32,33]$ and dynamic infiltration tests $[23,24]$. They have reported that the vents can certainly impact the unsaturated flow in porous media by functioning as air inlets or outlets, but in their dynamic experiments, the vents' effectiveness is still unclear in equilibrating pore air pressure with the atmospheric pressure. It is interesting to consider the rapid drainage experiments conducted by Hou et al. [29]. Hou et al. performed dynamic drainage experiment and modeling in an unsaturated soil column with an additional vent at the middle height of the vertical column with this vent open at the start of the test (note that the vent was connected to the inlet air source, rather than the surrounding atmosphere). In their dynamic drainage experiment, the vent failed to equilibrate pore air pressure with inlet air, and significant internal air pressure drops were observed.
In our dynamic infiltration experiments, from Figures 4 and 6 , for all combinations of vents open, before the wetting front passed the farthest open vent $\left(x_{\mathrm{far}}\right)$, the absence of air pressure increase suggests that, in this period, the vents in the experiments are able to equilibrate soil air pressure with atmospheric pressure. However, based on the findings presented by Hou et al. [29], it also should be noted that, if saturation of the medium is changing, dynamic flow of fluids would be expected to produce an internal air pressure gradient within the medium, even with a fully functioning vent. Therefore, under dynamic conditions, it is impossible that there is a complete air pressure equilibrium between any vent and pore air. Based on the measured air pressure data, for example, in Expt. \#3, before the saturation front passed the farthest open vent $\left(\mathrm{V}_{3}\right)$, from the above measurements (Figure 4), the difference in air pressure between the column end and the vent $V_{3}$ is low enough to be ignored $\left(\Delta p_{\mathrm{a}}^{\text {vent-end }}=0\right)$, while this was not true between the vent $\mathrm{V}_{3}$ and the pore air ahead of the front $\left(\Delta p_{\mathrm{a}}^{\text {front-vent }}\right)$. At any time of this period, the magnitude of the total pressure drops in the unsaturated portion of the packed column $\Delta p_{\mathrm{a}}^{\text {unsat }}$ (from the saturation front to the end of the column) can be assessed by the equation:

$$
\Delta p_{\mathrm{a}}^{\text {unsat }}=\Delta p_{\mathrm{a}}^{\text {front-vent }}+\Delta p_{\mathrm{a}}^{\text {vent-end }}
$$

If the saturation front position and inflow velocity are known at a certain time, by assuming a complete displacement, $p_{\mathrm{a}}^{\text {front }}$ can be expressed as

$$
\begin{aligned}
& p_{\mathrm{a}}^{\text {front }}=p_{\mathrm{w}}^{\text {front }}+\frac{1}{\alpha}, \\
& p_{\mathrm{w}}^{\text {front }}=p_{\mathrm{w}}^{\text {inlet }}-v_{\mathrm{w}}^{\text {inlet }} \frac{\rho_{\mathrm{w}} g L_{\mathrm{sat}}}{K_{\mathrm{sat}}},
\end{aligned}
$$

where $p_{\mathrm{w}}^{\text {front }}$ is the water pressure at the saturation front, $\alpha=8.72 \times 10^{-4} \mathrm{~Pa}^{-1}$ from the VG model is assumed to be approximate to the reciprocal of air entry pressure in the VG model, $p_{\mathrm{w}}^{\text {inlet }}$ is the measured water inlet pressure of $29812 \mathrm{~Pa}, v_{\mathrm{w}}^{\text {inlet }}$ is the infiltration rate, $L_{\text {sat }}$ is the length of the water-saturated zone, $\rho_{\mathrm{w}}=1000 \mathrm{~kg} / \mathrm{m}^{3}$ is the density of water, and $K_{\text {sat }}=1.76 \times 10^{-5} \mathrm{~m} / \mathrm{s}$ is the saturated hydraulic conductivity of the packing.

In Expt. \#3 with a single vent at $60 \mathrm{~cm}$ from the inlet, from the measured water saturation (Figure 3) and cumulative water imbibed (Figure 5), the inflow rate and the saturated zone length at the time when the front first reached point $\mathrm{P}_{1}(t=8 \mathrm{~min})$ are, respectively, $v_{\mathrm{w}}^{\text {inlet }}=1.69 \times 10^{-4} \mathrm{~m} /$ $\mathrm{s}$ and $L_{\mathrm{sat}}=0.3 \mathrm{~m}$, contributing to $\Delta p_{\mathrm{a}}^{\text {unsat }}=p_{\mathrm{a}}^{\text {front }}=p_{\mathrm{w}}^{\text {inlet }}+1 /$ $\alpha-\rho_{\mathrm{w}} g L_{\mathrm{sat}} \nu_{\mathrm{w}}^{\text {inlet}} / K_{\mathrm{sat}}=2720 \mathrm{~Pa}$. By using the same method, the calculated air pressure drops show that, in all the infiltration experiments, the magnitude of total gas pressure drops within the unsaturated portion of the columns is no more than about $3000 \mathrm{~Pa}$ at any time, far less than the inlet water pressure which strongly suggests that before the front reaches the farthest open vent, the internal 


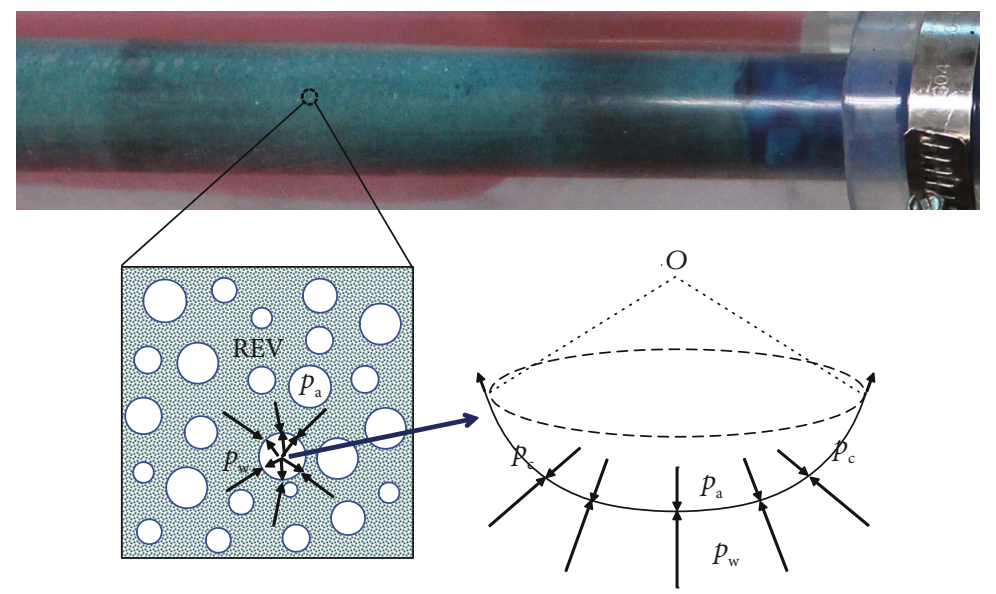

FIGURE 8: Schematic of air bubble in pores when a point approaches the saturated state, and the corresponding surface tension acting on the water-air interface.

viscous air pressure drops would not be expected to impact the dynamic infiltration significantly and the open vents work effectively.

Furthermore, it is important to note that equations (6) and (7) are only valid until the front reaches the farthest open vent, since after this period, the measured cumulative water imbibed and visual observations suggest that the air phase was likely to be continuously accumulated at the top of the horizontal column, and there was a continuous venting of air from the last open vent, which has been noted in the preceding section. In addition, from Figures 4 and 6, a gradual increase in the air pressure clearly shows that, while the vents are able to influence the flow behavior by functioning as air outlets, they cannot equilibrate pore air pressure with the surrounding atmosphere once the water front passes the vent.

Measurements of air pressure at the column point can provide a way for measuring the total pressure drop during imbibition. Therefore, a number of additional experiments with an addition of a gas pressure sensor installed at the column midpoint were conducted to measure the gas pressure at the midpoint of the column (please refer to the method of gas pressure measurement provided by Hou et al. [29]); however, all of these efforts failed due to air leak. This is because, compared to the dynamic drainage experiments conducted by Hou et al., all dynamic experiments conducted in this work are horizontal infiltration and focus on the influence of different air boundary conditions on water infiltration, so perfect control of air boundary condition is much more difficult. As reported in Hou et al. [29], they derived an equation for assessing the magnitude of the total pressure drop to the front in the case of vertical drainage. The fact that there was a good agreement between the measured results and the predicted value has proved this equation, which also confirms the validity of equation (7) because the equation for assessing the total pressure drop in the case of horizontal infiltration in this work is derived on the basis of Hou et al.'s work.

Clearly, if the column end is permeable to air, the vents are expected to reduce the internal air pressure effects during infiltration significantly. As a result, the retarding effect from the air pressure buildup is absent for the whole infiltration process and would not be expected to impact the infiltration behavior, which is consistent with the findings of some researchers $[2,22,24]$. However, unlike the open end case, the coupled air and water flow processes in columns with an airtight end can be divided into two completely different periods. Before the wetting front passes by the last open vent, the displaced air will be freely discharged from the open vents, and the internal air pressure effects on retarding the dynamic infiltration are negligible. After this period, presumably, there is some flow of air back to the vent along the top of the horizontal column, but the flow is constrained because of the high water saturation, the remaining air ahead of the front will be gradually compressed and confined, and the great increase in air pressure highlights the significant role of air pressure buildup in delaying water infiltration. Figure 9 illustrates the mechanism responsible for the role of airflow in water horizontal infiltration in an air-confined system.

It is also important to note that, for column systems with an air-permeable end $\left(x_{\mathrm{far}}=180 \mathrm{~cm}\right)$, from measurements, almost all air can escape from the column at the end of experiments. For $x_{\mathrm{far}}<180 \mathrm{~cm}$, the flow of air to the last vent would be impeded by the continuous water phase once the water passes by this vent. Comparing the values of theoretical peak air pressure to the measurements of air pressure indicates that a portion of air beyond must have escaped from the column system through open vents behind the wetting front. Based on the measurements, we can calculate the amount of air that would be vented $\omega_{\text {vent }}$ and compressed $\omega_{\text {comp }}=1-\omega_{\text {vent }}$ during the entire infiltration process; for example, in Expt. \#3, from Figure 5, $319.1 \mathrm{~cm}^{3}$ of water was imbibed which initially had about $406.6 \mathrm{~cm}^{3}$ of air $V_{\mathrm{a}}=$ $V_{\mathrm{c}} \phi\left(1-S_{\mathrm{w} 0}\right)$, where $V_{\mathrm{c}}$ is the total volume of the packings of $1272.3 \mathrm{~cm}^{3}, S_{\mathrm{w} 0}$ is the initial water saturation $(0.32)$, and $\phi$ is the sample porosity (0.47). Hence, if no air flows out after the water passes $\mathrm{V}_{3}$ until $t_{\mathrm{Q} \text {,peak }}$, the air in pores would be compressed from about $406.6 \mathrm{~cm}^{3}$ to $406.6-319.1=87.5 \mathrm{~cm}^{3}$. This should increase the pressure to $101 \mathrm{kPa} \times(406.6 / 87.5)$ 


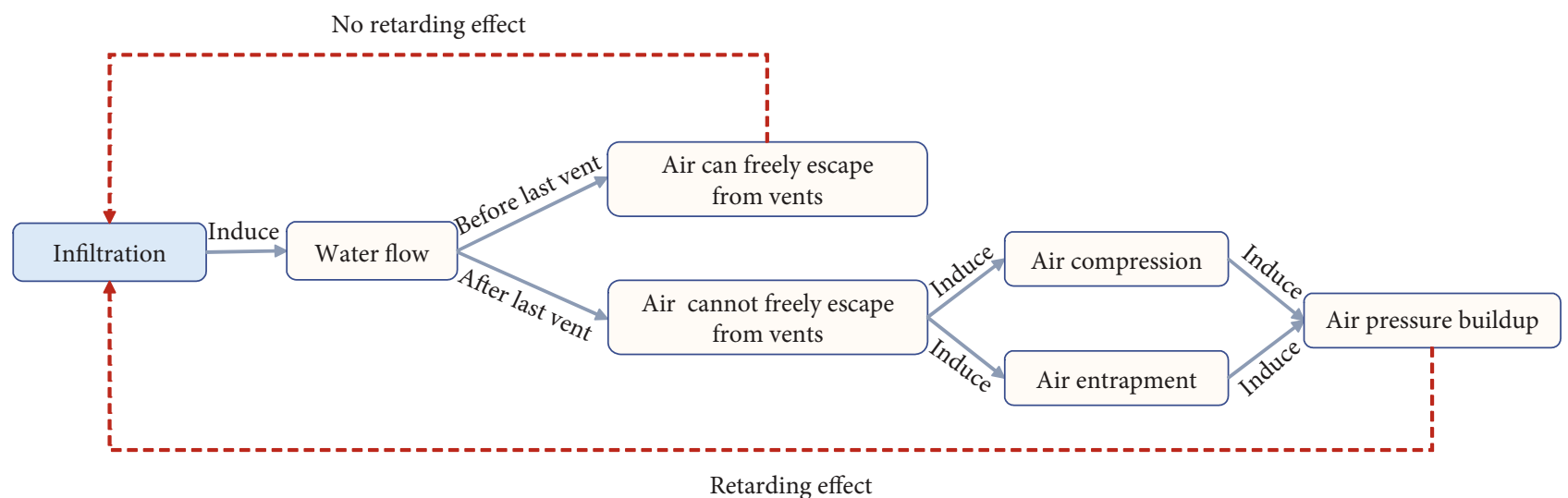

FIGURE 9: A conceptual figure illustrating the mechanism responsible for the role of airflow.

$=469.2 \mathrm{kPa}$ absolute. Since the peak air pressure is only about $129.01 \mathrm{kPa}$ absolute from Figure 4, as a molar ratio, the final moles, $n_{2}$, to the initial moles of air, $n_{1}$, is $n_{2 /}$ $n_{1}=\left(87.5 \mathrm{~cm}^{3} \times 129.01 \mathrm{kPa}\right) /\left(406.6 \mathrm{~cm}^{3} \times 101 \mathrm{kPa}\right)=0.27$. So about $73 \%$ of the air has been vented $(27 \%$ of air compressed). The total volume of vented air at atmospheric pressure is $V_{\text {vent }}=\omega_{\text {vent }} V_{\mathrm{a}}=294.8 \mathrm{~cm}^{3}$. By using the same method as before, the amount of air that has been vented $\omega_{\text {vent }}\left(V_{\text {vent }}\right)$ during Expts. \#1, \#2, \#4, and \#5 are, respectively, $96 \%\left(392 \mathrm{~cm}^{3}\right), 88 \%\left(356.2 \mathrm{~cm}^{3}\right), 98 \%\left(396.5 \mathrm{~cm}^{3}\right)$, and $81 \%$ $\left(329.6 \mathrm{~cm}^{3}\right)$. Evidently, Expts. \#1 and \#4 $\left(x_{\mathrm{far}}=180 \mathrm{~cm}\right)$ yield the largest $\omega_{\text {vent }}$, followed by Expts. $\# 2$ and $\# 5\left(x_{\mathrm{far}}=120 \mathrm{~cm}\right)$ and Expt. \#3 $\left(x_{\mathrm{far}}=60 \mathrm{~cm}\right)$, strongly suggesting that the closer the last open vent is to the water inlet (lower $x_{\mathrm{far}}$ ), the larger amount of air in pores will be compressed and entrapped; this is consistent with the air pressure results that a larger peak air pressure is also measured in a closer $x_{\text {far }}$.

From the above discussion, for $x_{\mathrm{far}}<180$, due to the presence of trapped air, the amount of water imbibed would give an average water saturation less than 1.0 at the end of the experiment. However, in Figure 3, the water saturation $S_{\mathrm{w}}$ values go to 1.0 for $\mathrm{P}_{1}, \mathrm{P}_{2}$, and $\mathrm{P}_{3}$. Presumably, this is in part due to the last measured point for water saturation $S_{\mathrm{w}}$ only at $170 \mathrm{~cm}$, rather than at the column end $(180 \mathrm{~cm})$. More importantly, most of the trapped air might accumulate at the top part of the horizontal column, but the measured probes were inserted into the middle side of the horizontal column. Hence, the probes were used only for measuring the middle part of the samples. In addition, the stainless steel sleeve connected with the column end might have a small amount of storage space for containing trapped air even if it has a minimum dead volume, which might also have a little contribution to this phenomenon.

In general, in a column system with a closed end, it is necessary to be cautious of air confinement effect, which may produce a great influence on delaying dynamic infiltration of water. This air confinement effect is likely to depend on factors such as the vent location, column size, inflow rate, and sand permeability. It also should be noted that for a specific experiment, the vent effectiveness can be significantly different in different periods of infiltration and strongly depends on the development of the water front.

\section{Conclusions}

We performed five dynamic infiltration experiments in horizontal sand columns considering various airtight conditions by the use of a single or multiple air vents, with a focus on the interactions among internal air pressure, inflow behavior, vent performance, and air entrapment effect. The results of this experimental study suggest that the infiltration behavior in unsaturated porous media with different airtight conditions can be dramatically differently influenced by internal air pressures and this air pressure effect is strongly controlled by the distance to the farthest air vent from which air can escape.

In column systems where the end is open, the air pressure effect would not be expected to influence water inflow behavior because the buildup in pressure is low enough to be ignored during the entire infiltration process. In a column system with a closed end, before the water front passes by the last open vent, the internal air pressure effects on retarding the water infiltration are also negligible; however, after this period, the remaining air ahead of the front will be gradually compressed and confined; the significant rise in air pressure highlights the great role of air compression in delaying water infiltration.

The vent impact on water inflow is strongly dependent on the development of the water front, which can be divided into two periods. Before the front passes the last open vent, the displaced air will be freely discharged from the open vents, and as a result, there is an equilibrium between soil air pressure and atmospheric pressure. After this period, while the vents can still function as air outlets, they fail to equilibrate the pore air with the atmosphere. The air pressure increases from the atmospheric pressure to different peaks. The closer the last open vent is to the water inlet, the larger the amount of air in pores will be entrapped and compressed, producing a larger peak air pressure and a stronger retarding effect on water inflow. In addition, for column systems with the same last open vent, the use of multiple air vents is expected to be more effective in reducing internal air pressure effect.

Some aspects need further investigation, especially concerning the dynamic infiltration or drainage in unsaturated 
porous media with a low-permeability layer, in which the potential effect of linear or nonlinear deformation of a low-permeability layer on the air-water flow is possible and cannot be excluded.

\section{Data Availability}

The experimental data used to support the findings of this study are included within the supplementary information files.

\section{Conflicts of Interest}

The authors declare that they have no conflicts of interest.

\section{Acknowledgments}

This work was support by the Major Research Plan of the National Natural Science Foundation of China (Project: Groundwater flow in the Yarlung Zanbo River and its evolution, Grant No. 91747204). The authors also gratefully appreciate the funding from China Three Gorges University (Grant No. XLD/2118), the funding from the Fundamental Research Funds for the Central Universities (Grant No. 2017B607X14), and the funding from the China Scholarship Council.

\section{Supplementary Materials}

Supplementary file (file name: Experimental data.zip): experimental data including five data files (file name: Fig. 3-7) in .xlsx format, corresponding to the experimental data used in Figures 3-7 in the manuscript. (Supplementary Materials)

\section{References}

[1] W. H. Green and C. A. Ampt, "Flow of air and water through soils," Journal of Agricultural Sciences, vol. 4, pp. 1-24, 1911.

[2] W. L. Powers, "Soil-water movement as affected by confined air," Journal of Agricultural Research, vol. 49, pp. 1125-1133, 1934.

[3] R. E. Horton, "An approach toward a physical interpretation of Infiltration-Capacity1," Soil Science Society of America Journal, vol. 5, pp. 399-417, 1941.

[4] D. R. Linden and R. M. Dixon, "Infiltration and water table effects of soil air pressure under border Irrigation1," Soil Science Society of America Journal, vol. 37, no. 1, pp. 94-98, 1973.

[5] H. Guo, J. J. Jiao, and E. P. Weeks, "Rain-induced subsurface airflow and Lisse effect," Water Resources Research, vol. 44, no. 7, 2008.

[6] H. P. Guo and J. J. Jiao, "Numerical study of airflow in the unsaturated zone induced by sea tides," Water Resources Research, vol. 44, no. 6, 2008.

[7] J. J. Jiao and H. Guo, "Airflow induced by pumping tests in unconfined aquifer with a low-permeability cap," Water Resources Research, vol. 45, no. 10, 2009.

[8] A. J. Peck, "Moisture profile development and air compression during water uptake by bounded porous bodies," Soil Science, vol. 100, no. 1, pp. 44-51, 1965.
[9] D. D. Adrian and J. B. Franzini, "Impedance to infiltration by pressure build-up ahead of the wetting front," Journal of Geophysical Research, vol. 71, no. 24, pp. 5857-5862, 1966.

[10] D. B. McWhorter, "Infiltration affected by flow of air," in Hydrology papers, no. 49, 1971Colorado State University, 1971.

[11] A. R. Jarrett, J. R. Hoover, and C. D. Paulson, "Subsurface drainage, air entrapment and infiltration in sand," Transactions of the ASAE, vol. 23, no. 6, pp. 1424-1427, 1980.

[12] E. G. Youngs and A. J. Peck, "Moisture profile development and air compression during water uptake by bounded porous BODIES," Soil Science, vol. 98, no. 5, pp. 290-294, 1964.

[13] J.-Y. Parlange and D. E. Hill, "Air and water movement in porous media," Soil Science, vol. 127, no. 5, pp. 257-263, 1979.

[14] J. Touma and M. Vauclin, "Experimental and numerical analysis of two-phase infiltration in a partially saturated soil," Transport in Porous Media, vol. 1, no. 1, pp. 27-55, 1986.

[15] C. S. Slater and H. G. A. Byers, Laboratory study of the field percolation rates of soils, no. 232, 1931 United States Department of Agriculture, 1931.

[16] E. P. Weeks, “The Lisse effect revisited," Groundwater, vol. 40, no. 6, pp. 652-656, 2002.

[17] Y. Li, K. Zhang, L. Hu, and J. Wang, "Numerical investigation of the influences of wellbore flow on compressed air energy storage in aquifers," Geofluids, vol. 2017, Article ID 9316506, 14 pages, 2017.

[18] J. J. Jiao and H. Li, "Breathing of coastal vadose zone induced by sea level fluctuations," Geophysical Research Letters, vol. 31, no. 11, 2004.

[19] Z. Zhou, M. Lin, Q. Guo, and M. Chen, "Scale effect and value criterion of the permeability of the interlayer staggered zones in the basalt of Jinsha River basin, China," Hydrogeology Journal, vol. 26, no. 5, pp. 1731-1748, 2018.

[20] Z. F. Zhou, M. W. Li, C. Zhuang, and Q. N. Guo, "Impact factors and forming conditions of valley deformation of Xiluodu Hydropower Station," Journal of Hohai University (Natural Sciences), vol. 46, no. 6, pp. 497-505, 2018.

[21] G. R. Free and J. J. Palmer, "Interrelationships of infiltration, air movement, and pore size in graded silica sand," Soil Science Society of America Journal, vol. 5, pp. 390-398, 1940.

[22] L. G. Wilson and J. N. Luthin, "Effect of air flow ahead of the wetting front on infiltration," Soil Science, vol. 96, no. 2, pp. 136-143, 1963.

[23] G. Vachaud, M. Vauclin, D. Khanji, and M. Wakil, "Effects of air pressure on water flow in an unsaturated stratified vertical column of sand," Water Resources Research, vol. 9, no. 1, pp. 160-173, 1973.

[24] H. Latifi, S. N. Prasad, and O. J. Helweg, "Air entrapment and water infiltration in two-layered soil column," Journal of Irrigation and Drainage Engineering, vol. 120, no. 5, pp. 871891, 1994.

[25] A. C. Liakopoulos, Transient Flow through Unsaturated Porous Media, University of California, Berkeley, CA, USA, 1964.

[26] N. R. Fausey and R. D. Brehm, "Shallow subsurface drainagefield performance," Transactions of the ASAE, vol. 19, no. 6, pp. 1082-1084, 1976.

[27] J. L. Suhr, A. R. Jarrett, and J. R. Hoover, “The effect of soil air entrapment on erosion," Transactions of the ASAE, vol. 27, no. 1, pp. 0093-0098, 1984. 
[28] X. Kuang, J. J. Jiao, L. Wan, X. Wang, and D. Mao, “Air and water flows in a vertical sand column," Water Resources Research, vol. 47, no. 4, 2011.

[29] L. Hou, B. E. Sleep, and T. C. G. Kibbey, "Gas pressure gradients in unsaturated porous media and the assumption of infinite gas mobility," Water Resources Research, vol. 51, no. 7, pp. 5623-5639, 2015.

[30] K. H. Tan, Soil Sampling, Preparation, and Analysis, CRC Press, 2005.

[31] M. T. Van Genuchten, "A closed-form equation for predicting the hydraulic conductivity of unsaturated soils," Soil Science Society of America Journal, vol. 44, 1980.

[32] J. S. Rogers and A. Klute, "The Hydraulic conductivity-water content relationship during nonsteady flow through a sand Column1," Soil Science Society of America Journal, vol. 35, no. 5, pp. 695-700, 1971.

[33] F. Stauffer, "Time dependence of the relations between capillary pressure, water content and conductivity during drainage of porous media," in Proceedings of the IAHR Symposium on Scale Effects in Porous Media, Thessaloniki, Greece, August 1978. 

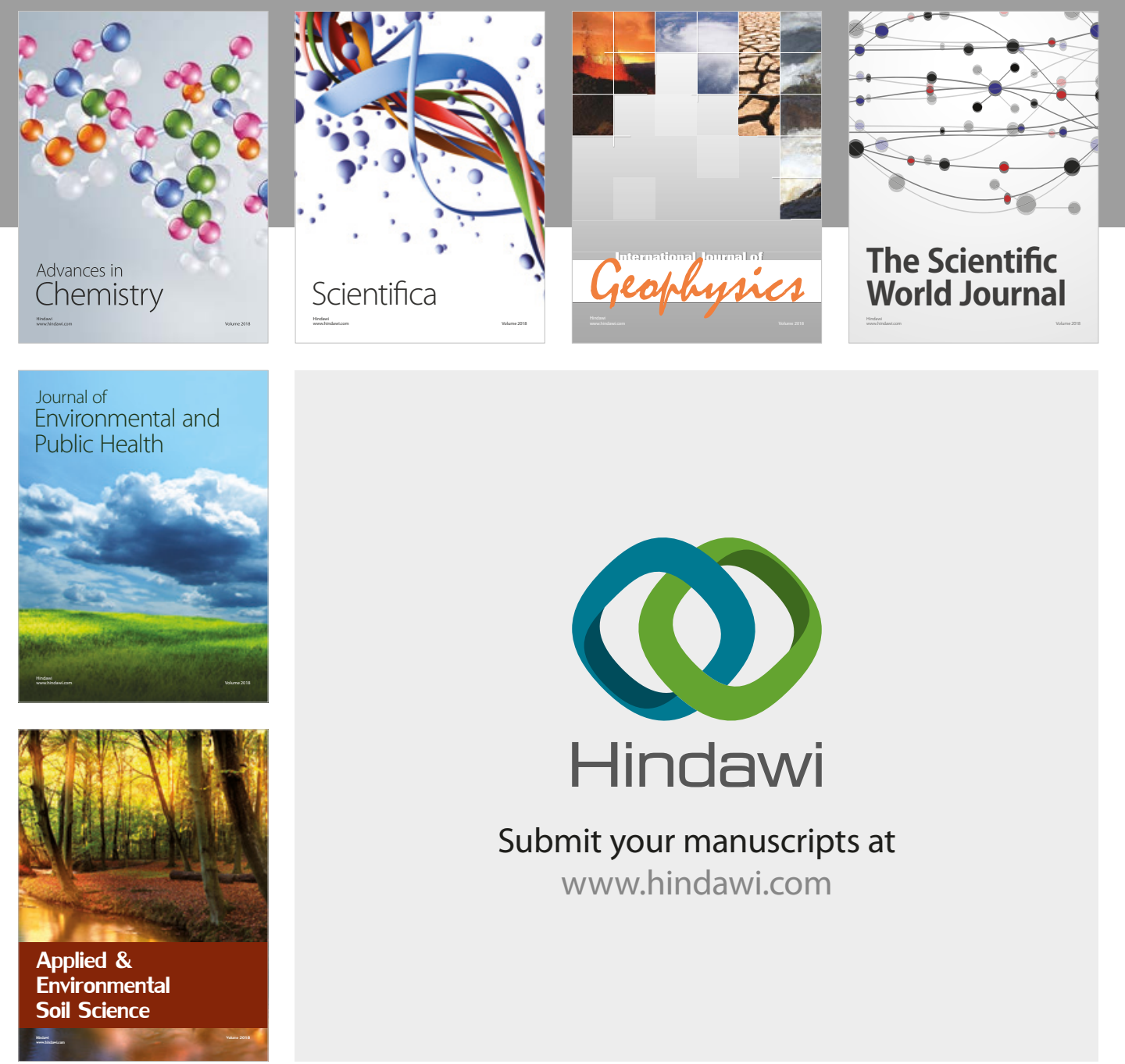

The Scientific

\section{World Journal}
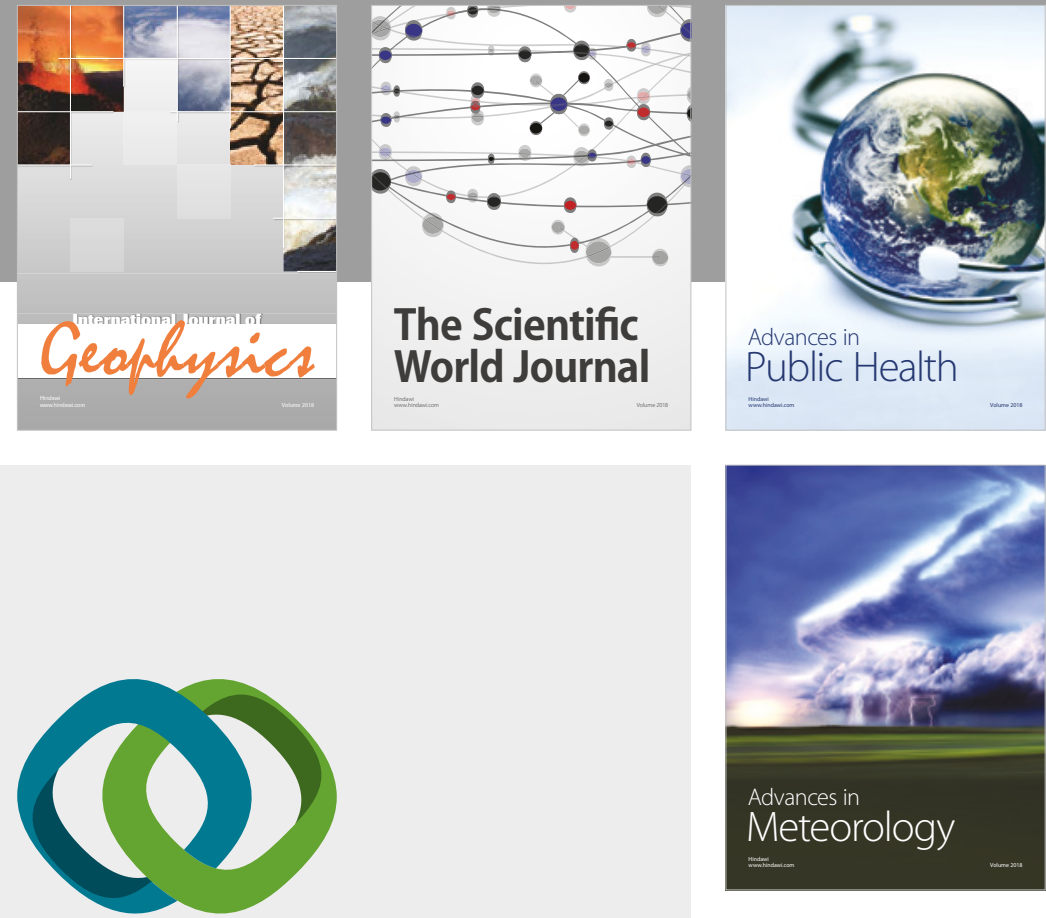

Advan

Public Health

\section{Hindawi}

Submit your manuscripts at

www.hindawi.com
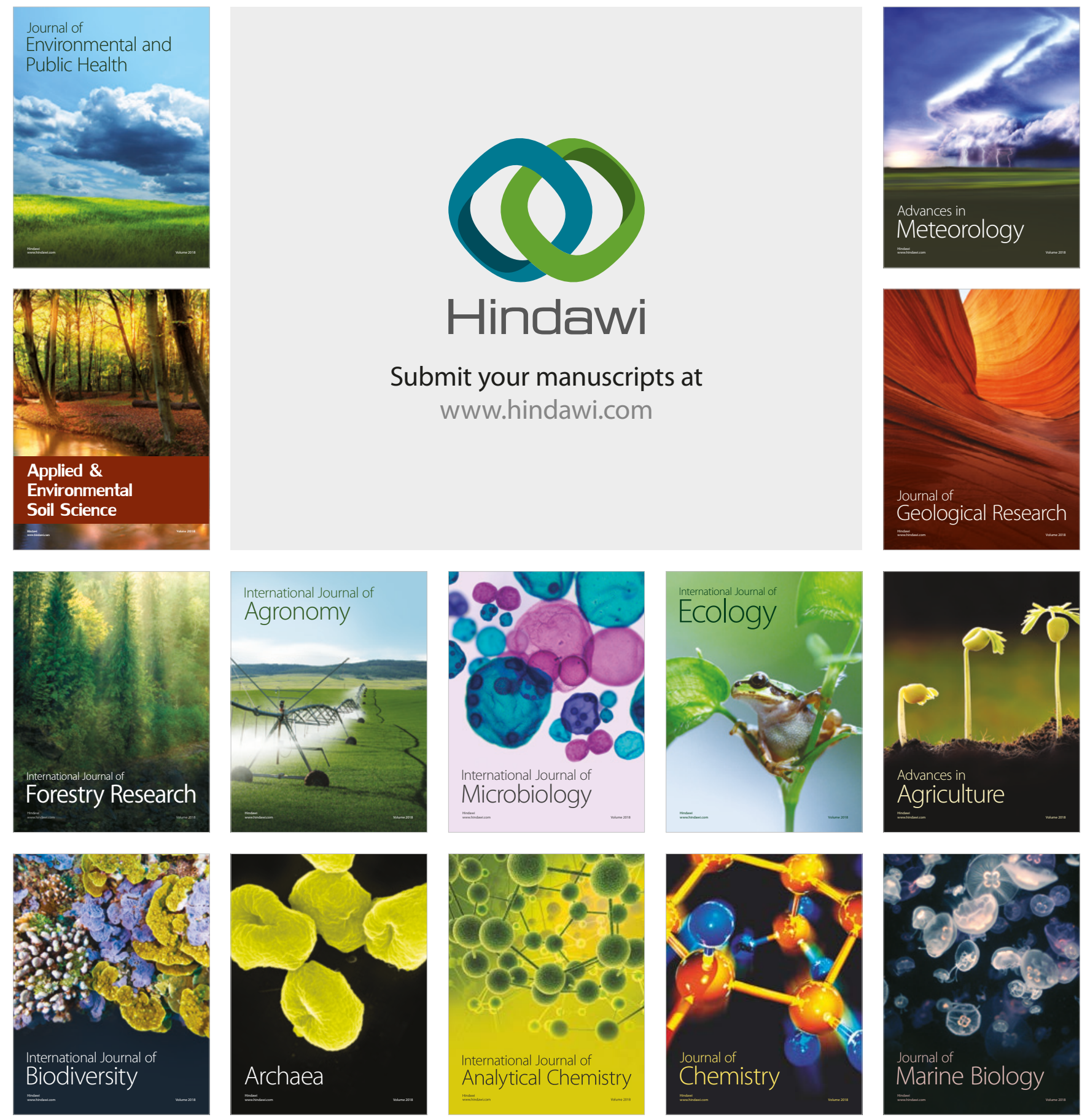